\title{
Electro-Optical Displays
}

\author{
Mohammad A. Karim, MEMBER SPIE \\ University of Dayton \\ Center for Electro-Optics \\ and \\ Electrical Engineering Department \\ 300 College Park Avenue \\ Dayton, Ohio 45469-0226
}

A picture is as good as a thousand words. No wonder the success of many of our engineering endeavors is determined in terms of a displayed end product. Interestingly, however, display devices serve both as input and output to information processing systems. Finally, our eyes have to make sense of the displayed information. To what extent the display devices and the displayed information are compatible to our eyes and brains is thus an important issue to be ascertained. The 11 papers in this special Optical Engineering issue on Electro-Optical Displays is fortuitously categorized into three subareas: display systems development, display systems integration issues, and display systems characterization issues.

The first four papers deal with the design and development of new display systems suitable for both military and civilian applications. In the first paper, K. E. Jachimowicz and R. S. Gold use both time and space multiplexing by polarizating with color to convert a two-dimensional display into a three-dimensional stereoscopic display. This is followed by a paper by $R$. Hockenbrock in which the author introduces the design of two advanced color cathode ray tubes (CRTs) for use as heads-down displays in jet fighter and helicopter applications. These taut shadow mask CRTs are significantly advanced in terms of brightness, resolution, and ruggedness. In the third paper, J. G. Droessler and D. J. Rotier describe the development of a new helmet-mounted display (HMD) that uses a tilted catadioptric combiner. The tilted cat display allows a wide field of view (FOV) and has brightness characteristics markedly improved over the conventional catadioptric approach. Finally, in the fourth paper, M. L. Thomas, R. Robinson, W. P. Siegmund, and S. E. Antos review the issues and characteristics of state-of-the-art fiber optic HMDs.

The next four papers deal with the practical aspects of integration, limitations, and characteristics of displays. In the first paper, C. E. Rash and R. W. Verona discuss the consequences of internal cockpit lighting on the night operation capability of imaging systems based on image intensification. This paper elaborates the efforts to address the fact that the internal cockpit lighting may activate the automatic gain control circuits of the intensification tubes. In the second paper, M. J. Wells and $M$. Venturino discuss the criteria for selecting an optimal FOV for HMDs. The authors have studied the interrelation between the performance and head movements when an HMD is being used. Next, M. L. Gao, S. H. Zheng, M. A. Karim, and D. L. Moon quantify the characteristics of image degradation associated with the phosphor based displays used in dynamic environments. The paper identifies filters that restore motion-degraded images when incorporated into the display systems. Finally, E. Peli describes problems associated with the use of monocular displays, such as rivalry of the image in each eye and motion-degradation of images caused by the relative movement of device and eye.

The third subarea of this special issue concerns yet another important aspect of display technology, namely, the development of analytical as well as experimental tools for the characterization of display devices. In the first paper, J. C. Feltz develops the modulation transfer function (MTF) and contrast transfer function for the characterization of discrete display devices for both static and dynamic environments. The analysis has been used in the characterization of displays based on charge-coupled devices. This is followed by a work by M. L. Gao, M. A. Karim, and S. H. Zheng in which they develop a device nonspecific minimum resolvable temperature difference model for the evaluation of infrared imaging/display systems. The model has been used to identify analytical means for evaluating both scanning and staring detectors. Finally, T. S. Lomheim, L. W. Schumann, R. M. Shima, J. S. Thompson, and W. F. Woodward describe an experiment for characterizing scanned time-delayand-integrate charge-coupled imagers. Their experimental data provide insights into how the MTF is governed by the many parameters that arise due to the very nature of the imaging system.

In conclusion, this issue is well balanced and reports the ongoing efforts on displays at different laboratories. I would like to thank the many contributors and reviewers for their dedication. Without their help, this special issue would not have been possible.

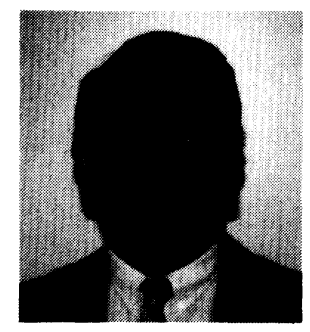

Mohammad A. Karim is an associate professor with joint appointments in the Electrical Engineering Department and the Center for Electro-Optics at the University of Dayton. He received his BS degree in physics from the University of Dacca (Bangladesh) in 1976, and MS degrees in physics and electrical engineering and the Ph.D. degree in electrical engineering from the University of Alabama in 1978, 1979, and 1981, respectively. Dr. Karim is the author or coauthor of more than 90 published papers. He authored the textbook Electro-Optical Devices and Systems (1990) and coauthored the textbook Digital Design: A Pragmatic Approach (1987). His research interests include optical computing/processing, optical systems design, infrared systems, digital systems/ processing, displays, and integrated optics. He is a member of SPIE and OSA and the faculty advisor of the University of Dayton's SPIE student chapter. 